\title{
A Study on Manasement Plan of Korea Garden Show through Surveying Garden Experts
}

\author{
Woo Kyung Choi ${ }^{1,2}$, You Mi Lee ${ }^{1}$, Jeong Hwa Song ${ }^{1}$, and Hye Young Jin $^{1 *}$ \\ ${ }^{1}$ Korea National Arboretum, Pocheon 11186, South Korea \\ ${ }^{2}$ Department of Environmental Horticulture, University of Seoul, Seoul 02504, South Korea
}

\begin{abstract}
This study aims to present direction for management of Korea Garden Show based on a survey of 105 experts in garden from a variety of backgrounds. Considerations for improving management of Korea Garden Show are as follows. First, when inviting applications for Garden Show, presenting a specific theme such as existing management method can encourage people to present more ideas from limited diversity. Second, it is the greatest time to hold the Garden Show from April to May in consideration of the diversity of plants and flowering time, and two week period is considered to be sufficient for the show according to the matters of operation and management of the show garden and requests of experts. Third, the show should be held in a designated place and after promoting sustainability and improving public awareness of the show. It should be also developed to show extended base of a garden and a variety of local characteristics, and held in provincial and municipal areas. Forth, industry-linked contents should be strengthened in the process of organizing the garden show. A symposium should be organized to introduce materials of garden industry including high-tech materials and new plant varieties and provide information about garden trends, and the show should perform its role as a platform for establishing garden culture.
\end{abstract}

Key words: expo, festival, garden cultures, management plan

\section{I . Introduction}

The increase in national income has led to higher needs for healthy and relaxing life and culture in nature, and the demand for gardens and garden culture also increased with the expansion of awareness on gardens as part of life and culture. Moreover, the International Garden Expo Suncheon Bay Korea 2013 raised national interest in gardens, and since then the demand for gardens and infrastructures to tend those gardens has increased consistently (Chung et al., 2015). In line with these demands, the central and local governments are currently striving to expand the garden culture by leading events such as garden expos and shows (Song et al., 2016). Before the International Garden Expo Suncheon Bay Korea, the events were mostly focused on the floricultural industry such as International Horticulture Goyang Korea, Anmyeondo International Flower Expo, Gurye Maehwa Festival, and Hampyeong Grand Chrysanthemum Festival (You, 2013), but now garden-

Received on March 31, 2017. Revised on April 10, 2017.

Accepted on April 20, 2017.

*Comesponding author: jinhye0@korea.kr centered exhibitions are increasing remarkably nationwide, such as Gyeonggi Garden Culture Expo, Korea Garden Show, Seoul Garden Show, and Hanpyeong Garden Festival. Garden shows held overseas such as Chelsea Flower Show have also been expanded to the territory that combined gardens with art today, which is a shift from the horticultural contents focused on flower production in the earlier days (Chung et al., 2015), contributing to the promotion of garden culture. Many countries are implementing policies to turn gardens into cultural products and use them as a brand for national publicity. The trend of turning gardens into a cultural product can be proved by frequent events like the world garden expos and creation of or participation in traditional gardens to promote the culture of the relevant country (Yoon et al., 2014). There is Chelsea Flower Show in England, Le Festival International des de Chaumont-sur-Loire in France, Bundesgartenschau and Internationale Gartenschau in Germany, and Floriade in the Netherlands that is held every 10 years, securing their places as the main garden expos that represent Europe.

Previous studies on garden shows are conducted in the operational and strategic perspectives for garden expos. Yoon 
(2009) introduced the characteristics of Chelsea Flower Show (hosting organization history, size and operation method, judgment criteria) and studied the design trends.

For research on branding cities and enhancing images, You and Yang (2013) examined the study on garden expos in Korea as a strategy of regional revitalization. Lee et al. (2015) analyzed the effects of hosting the International Garden Expo Suncheon Bay Korea on changes in Suncheon's city brand and image, and mentioned that it provides an opportunity for Suncheon to build a new city image. Lee (2014) examined the characteristics and factors affecting the process in which the plan for the International Garden Expo Suncheon Bay Korea is being specified into a regional policy, through which it was discovered that there were certain outcomes in improving the city's image, securing the public goods such as Suncheonman Bay National Garden, and building leadership in the community that carried forward urban policies valuing the environment.

For research on analysis of gardens at garden expos and detailed designs such as plantations, Park and Lee (2014) conducted a study on the healing effects of gardens with cases of 'healing gardens' at the Korea Garden Show. Jeong (2015) analyzed the planting designs of the International Garden Expo Suncheon Bay Korea, determined the trends and techniques of planting design, and laid the groundwork for the development of herbaceous ornamental planting designs.

As such, current studies on garden expos are mainly about regional revitalization such as the International Garden Expo Suncheon Bay Korea or planting design and exhibition effects (healing effects) focusing on the gardens, with insufficient research on the management methods or improvements for actual garden expos. In fact, the Korea Garden Show has been managed for three years with many controversies over the management method such as venue, period and theme selection. State-run garden shows raise great expectations for the citizens in terms of their roles, such as publicity as well as expansion of garden culture and sharing of information, which is why it is necessary to study the detailed management plans for the state to find its roles accordingly.

This study will survey the views of garden-related experts from all sorts of backgrounds to come up with internally stable management plans and set the direction for improvement of the Korean Garden Show, which is supported by the government

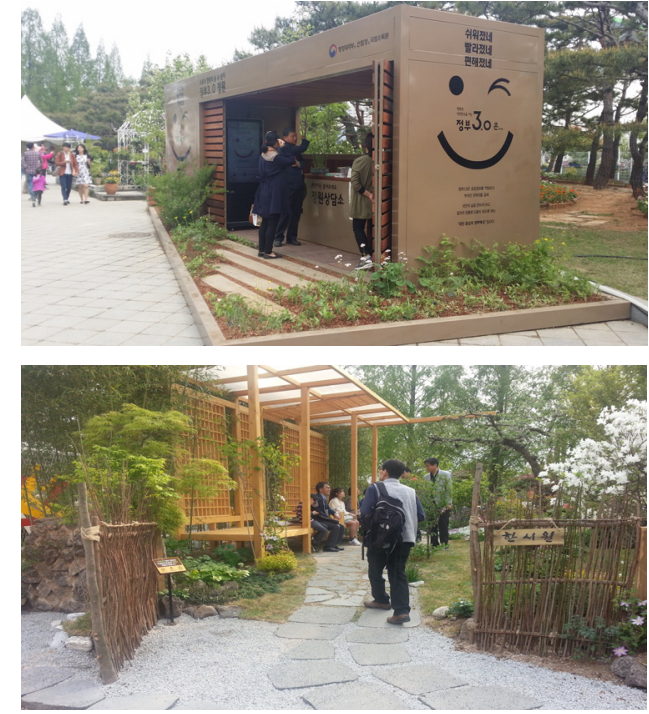

Fig. 1. 2016 Korea Garden Show.

(Korea Forest Service) and is also the gateway to becoming a garden designer in Korea.

\section{Research method}

\section{Selection of research subjects}

In general, expositions and exhibitions are commonly referred to as "show, trade show, fair, expo, exposition, etc." (You and Yang, 2013). Among them, "exposition, festival and show" are the most commonly used terms for garden expos, with "show" being the term that is particularly used widely in England, Germany and the US (Yoon, 2009). Thus, this study uses the term "show" among the mixed use of different terms.

The Korea Garden Show was held three times from 2014 to 2016, and is hosted at the venue of the International Horticulture Goyang Korea from late April to early May (for 17 days). Every year there is a different theme (2014: Healing Garden, 2015: Garden in My Life, 2016: K-garden) with the participation of garden designers involved in various genres in Korea, and thus the show performs the role of finding competent garden designers and promoting gardens to the citizens.

This study was conducted on experts related to garden shows in Korea (total 105). They include garden designers who participated in the Korea Garden Show (29.5\%), related public officials (17.1\%), professors (27.6\%), and others (25.6\%), 
Table 1. Respondent attribute.

\begin{tabular}{|c|c|c|c|}
\hline & Division & Number & Ratio (\%) \\
\hline \multirow{2}{*}{ Gender } & Male & 55 & 52.4 \\
\hline & Female & 50 & 47.6 \\
\hline \multirow{5}{*}{ Age } & $20-29$ & 15 & 14.3 \\
\hline & $30-39$ & 38 & 36.2 \\
\hline & $40-49$ & 35 & 33.3 \\
\hline & $50-59$ & 16 & 15.2 \\
\hline & $60<$ & 1 & 1.0 \\
\hline \multirow{7}{*}{ Occupation } & Management & 12 & 11.4 \\
\hline & Self-management & 18 & 17.1 \\
\hline & Office job & 24 & 22.9 \\
\hline & Agriculture job & 5 & 4.8 \\
\hline & Specialized job & 37 & 35.2 \\
\hline & Student & 4 & 3.8 \\
\hline & Other & 5 & 4.8 \\
\hline Education & Graduation university & 105 & 100 \\
\hline \multirow{8}{*}{ Major } & Systematic botany & 7 & 6.7 \\
\hline & plant ecology & 4 & 3.8 \\
\hline & Biology & 3 & 2.9 \\
\hline & Engineering & 3 & 2.9 \\
\hline & Forest resources & 11 & 10.5 \\
\hline & Landscape architecture & 59 & 56.2 \\
\hline & Horticulture & 12 & 11.4 \\
\hline & Other & 6 & 5.7 \\
\hline \multirow{5}{*}{$\begin{array}{l}\text { Related } \\
\text { field }\end{array}$} & Garden designer & 31 & 29.5 \\
\hline & Public official & 18 & 17.1 \\
\hline & Garden Show Judge & 2 & 1.9 \\
\hline & Professor & 29 & 27.6 \\
\hline & Other & 25 & 23.8 \\
\hline
\end{tabular}

classified by occupation (office job, management, public official, specialized job, etc.) and major (landscape architecture, horticulture, systematic botany, etc.).

The survey was conducted by visits and emails from June 21, 2016 to September 10, 2016 (Table 1).

\section{Survey and method of analysis}

To develop the questionnaire to set the direction for the Korea Garden Show, the management methods of the Chelsea Flower Show, Le Festival International des de Chaumont-surLoire, and Bundesgartenschau were examined.
Table 2. Survey items

\begin{tabular}{lc}
\hline \multicolumn{1}{c}{ Division } & Items \\
\hline $\begin{array}{l}\text { Introduction of garden trend } \\
\text { Function }\end{array}$ & $\begin{array}{c}\text { Material and human resources information } \\
\text { about the garden } \\
\text { Spreading Garden Cultures }\end{array}$ \\
Suggestion of Topic \\
Frequency of a garden show \\
Provincial tour of a garden show \\
Garden show tour \\
Time to hold a garden show \\
Management \\
Method for holding garden show \\
Garden designer invitation method \\
Scope of a garden show
\end{tabular}

The Chelsea Flower Show in England is held for four days at the end of May each year, without setting a specific theme when inviting public participation for the show gardens. All the gardens are demolished after the show, and there is also a section in floriculture such as breeding and cultivating. Le Festival International des de Chaumont-sur-Loire in France is held every year for 6 months (mid-April to mid-October), focusing on garden designs and garden as art by presenting certain themes. Bundesgartenschau in Germany is held biennially, touring around the big and small cities of Germany and presenting plans to reform the city's image and use the gardens as greens. Based on these contents, a questionnaire was developed to determine the management plan for the Korea Garden Show by experts related to gardens.

The survey is classified into 1) Purpose and Function, and 2) Garden Show Management (suggestion of topic, frequency, time, provincial tour, period, method, and scope of the garden show), and each survey category is classified by the content of the survey, with subordinate items in each category (Table 2). The subordinate items for each category are arranged in either multiple-choice or short-answer form.

Collected data are analyzed using SPSS Statistics 18 version, with the following analysis methods by category of each item. Crosstabs analysis was conducted by gender, role in the garden show and major in the form of frequency (person) and percentage (\%), and the Chi-square independent test was conducted to determine whether there is statistical significance in the 
difference of responses among groups. Without a significant difference, the results of the analysis were not presented in the table.

\section{Result and discussion}

\section{Purpose and function of garden shows}

In the survey on the purpose and function of garden shows, $68.2 \%$ of all respondents said it is for spreading the garden culture. By role of garden shows, $73.1 \%$ of professors, $69.2 \%$ of public officials, and $60.7 \%$ of garden designers gave that response, which was significantly higher than the rate of responses such as introduction of the garden trend, and material and human resources information about gardens. This indicates that people from different backgrounds lay most stress on the need to spread the garden culture (Table 3). Chung et al., (2015) claimed the need to flourish the garden culture as a cultural industry, and that the flow and trend of times are already raising great interests and various attempts regarding such garden culture industry. Moreover, the world-renowned Chelsea Flower Show does not merely introduce gardens and horticulture, but reflect and express the society and culture of contemporary times (Yoon, 2009 ; Park and Park, 2011). In this context, the Korea Garden Show will also have a remarkable effect on the Korean garden culture industry as well.

\section{Garden show management method}

1) Suggestion of the topic

The result of Pearson's chi-squared test shows that there was statistical significance in the views about the need to present a topic when holding a garden show by gender and role in garden show (Table 4). More male respondents said it is necessary to suggest the topic, and a greater ratio of garden designers thought topic suggestion is necessary, whereas others (public officials and professors) showed a lower ratio. Male respondents said it is necessary to provide unity in the garden show as well as fair judging standards, and that social issues and garden trends shall be reflected on the topic. Meanwhile, female respondents tended to prefer various creative and original works. Since artists are screened to be able to build a garden for the garden show, they seem to want more accurate guidelines for judgment and evaluation, while public officials and professors

Table 3. Purpose and function of a garden show based on survey.

\begin{tabular}{|c|c|c|c|c|c|c|}
\hline Division & $\begin{array}{l}\text { Garden } \\
\text { Designer }\end{array}$ & $\begin{array}{l}\text { Public } \\
\text { officer }\end{array}$ & $\begin{array}{c}\text { Garden } \\
\text { Show Judge }\end{array}$ & Professor & Other & Total \\
\hline Introduction of garden trend & $5(17.9)$ & - & - & $2(7.7)$ & $1(6.25)$ & $8(9.4)$ \\
\hline Spreading Garden Cultures & $17(60.7)$ & $9(69.2)$ & $2(100.0)$ & $19(73.1)$ & $11(68.7)$ & $58(68.2)$ \\
\hline
\end{tabular}

Table 4. A need to present a theme of garden show based on survey.

\begin{tabular}{|c|c|c|c|c|c|c|c|c|}
\hline \multirow[b]{2}{*}{ Division } & \multicolumn{2}{|c|}{ Gender } & \multicolumn{6}{|c|}{ Related field } \\
\hline & Male & Female & $\begin{array}{l}\text { Garden } \\
\text { Designer }\end{array}$ & $\begin{array}{l}\text { Public } \\
\text { officer }\end{array}$ & $\begin{array}{c}\text { Garden } \\
\text { Show Judge }\end{array}$ & Professor & Other & Total \\
\hline Freedom of topic & $15(27.3)$ & $21(42.0)$ & $7(22.6)$ & $6(33.3)$ & $1(50.0)$ & $11(37.9)$ & $12(48.0)$ & $36(34.3)$ \\
\hline Other & $3(5.4)$ & $13(26.0)$ & $1(3.2)$ & $4(22.2)$ & - & $5(17.1)$ & $6(24.0)$ & $17(16.2)$ \\
\hline
\end{tabular}


prefer to see more liberal and diverse forms of gardens. Kwon (2009) stated that Le Festival International des de Chaumontsur-Loire presented a theme for the show every year, and the exhibited gardens form a harmony within diversity, and that presenting a certain theme every year can invite new ideas through diversity within limitations, help artists come up with various techniques and experimental materials, and broaden the scope of application of plant materials.

\section{2) Frequency and time of holding garden shows}

The result of Pearson's chi-squared test shows that there was statistical significance in the views about the frequency of holding garden shows by major $(p=0.054)$. The rate of respondents in landscape architecture and horticulture saying that it is necessary to hold garden shows every year was significantly higher than others (systematic botany, biology, etc.) (Table 5). Landscape architecture and horticulture majors mostly claimed the need to increase awareness by regularly holding the shows and introduce the rapidly changing garden trends. Systematic botany and biology majors seem to want to create garden shows with internal stability by thoroughly preparing materials such as plants with enough time to prepare. Jeong and Oh (2016) claimed that the biennial Gyeonggi Garden Culture Expo changed into an annual event starting from 2017, which increased awareness as well as the opportunity for the public to participate. Since it is still a rare event in Korea, it is expected to increase the number of visitors for quite some time with all the public interest and participation. Table 6 shows that there is a statistically significant difference in the views about when to hold garden shows by major $(p=0.058)$. Plant ecology majors preferred 'June-August,' while others (forest resources, landscape architecture and horticulture majors) preferred 'April-May.' This seems to be in consideration of the diversity of plant materials and blossoming flowers in April-May.

\section{3) Provincial tour of garden shows}

The result of conducting a survey on whether there is a provincial tour of garden shows is shown in Table 7, which

Table 5. Frequency of holding garden show based on survey

\begin{tabular}{|c|c|c|c|c|c|c|c|c|c|}
\hline Division & $\begin{array}{c}\text { Systematic } \\
\text { botany }\end{array}$ & $\begin{array}{c}\text { Plant } \\
\text { ecology }\end{array}$ & Biology & Technology & $\begin{array}{c}\text { Forest } \\
\text { resources }\end{array}$ & $\begin{array}{l}\text { Landscape } \\
\text { architecture }\end{array}$ & Horticulture & Other & Total \\
\hline 1year & $4(57.1)$ & $3(75.0)$ & $1(33.3)$ & $2(66.7)$ & $8(72.7)$ & $38(66.7)$ & $10(83.3)$ & $6(100.0)$ & $72(69.9)$ \\
\hline 2year & $1(14.3)$ & - & $2(66.7)$ & $1(33.3)$ & $2(18.2)$ & $13(22.8)$ & $2(16.7)$ & - & $21(20.4)$ \\
\hline 3year & $2(28.6)$ & - & - & - & $1(9.1)$ & $4(7.0)$ & - & - & $7(6.8)$ \\
\hline 5year & - & $1(25.0)$ & - & - & - & - & - & - & $1(1.0)$ \\
\hline Other & - & - & - & - & - & $2(3.5)$ & - & - & $2(1.9)$ \\
\hline Total & $7(100.0)$ & $4(100.0)$ & $3(100.0)$ & $3(100.0)$ & $11(100.0)$ & $57(100.0)$ & $12(100.0)$ & $6(100.0)$ & $103(100.0)$ \\
\hline$X^{2}(p)$ & \multicolumn{9}{|c|}{$41.018 \mathrm{a}\left(.054^{*}\right)$} \\
\hline
\end{tabular}

${ }^{*} p<0.10,{ }^{* *} p<0.05,{ }^{* * *} p<0.01$.

Table 6. Time to hold a garden show based on survey.

\begin{tabular}{|c|c|c|c|c|c|c|c|c|c|}
\hline Division & $\begin{array}{c}\text { Systematic } \\
\text { botany }\end{array}$ & $\begin{array}{c}\text { Plant } \\
\text { ecology }\end{array}$ & Biology & Technology & $\begin{array}{l}\text { Forest } \\
\text { resources }\end{array}$ & $\begin{array}{l}\text { Landscape } \\
\text { architecture }\end{array}$ & Horticulture & Other & Total \\
\hline April-May & $5(71.4)$ & $1(25.0)$ & $2(66.7)$ & $2(66.7)$ & $8(72.7)$ & $43(72.9)$ & $11(91.7)$ & $6(100.0)$ & $78(74.3)$ \\
\hline June-August & $1(14.3)$ & $3(75.0)$ & $0(0.0)$ & - & $3(27.3)$ & $11(18.6)$ & - & - & $18(17.1)$ \\
\hline September-November & - & - & $1(33.3)$ & - & - & $3(5.1)$ & - & - & $4(3.8)$ \\
\hline Other & $1(14.3)$ & - & - & $1(33.3)$ & - & $2(3.4)$ & $1(8.3)$ & - & $5(4.8)$ \\
\hline Total & $7(100.0)$ & $4(100.0)$ & $3(100.0)$ & $3(100.0)$ & $11(100.0)$ & $59(100.0)$ & $12(100.0)$ & $6(100.0)$ & $105(100.0)$ \\
\hline
\end{tabular}

${ }^{*} p<0.10,{ }^{* *} p<0.05, * * * p<0.01$. 
reveals significance in the statistical analysis of preferred venues by occupation of the respondents $(p=0.038)$. Garden designers preferred a fixed place, whereas others (public officials and professors) preferred provincial tour. This suggests that garden designers focus on the increase in public awareness, sustainability and stability of the garden show when holding the show in a fixed place, while public officials and professors chose circulating place due to reasons such as expanding the base of gardens, diversity of distinctive regional garden shows, and difficulty in access. There is a case in which urban regeneration ended up in success by holding "Landes gartenschau" (LAGA) as a culture-led urban regeneration strategy in a deteriorated industrial space neglected in the middle of Ruhr in Germany (Park, 2013). It seems that the tour of the venue will be determined by the purpose of holding the garden show.

\section{4) Period of holding garden shows}

There was statistical significance in the views of respondents regarding the period of holding garden shows by occupation (0.001) (Table 8).

A high ratio of garden designers thought it is necessary hold the show for 2 weeks, while others showed significant differences in ratio (public officials and professors). This indicates that garden designers think 2 weeks of exhibition is enough due to difficulty in management after forming the gardens. Moreover, unlike provincial garden shows managed independently, the Korea Garden Show is held with the International Horticulture Goyang Korea and is thus affected by its period, which resulted in many responses that 2 weeks is adequate. The Chelsea Flower Show had been held for three days from Tuesday to Thursday, but it has been extended to Friday upon the request of participants since 1926 (Geddes-Browun and Leslie, 2005). It seems necessary for the Korea Garden Show to also flexibly adjust the operating period depending on the needs of the participants.

\section{5) Method of inviting garden show designers}

There was statistical significance in the views about hot to hold garden shows by occupation (0.000) (Table 9). Garden designers preferred 'inviting domestic garden designers,' while others (public officers, professors, etc.) preferred 'inviting domestic and foreign garden designers and holding contest exhibits.' This is to expand the scope of activities for current garden designers beyond applying for the contest exhibits within the garden show.

Table 7. Provincial tour of a garden show based on survey.

\begin{tabular}{lcccccc}
\hline \multicolumn{1}{c}{ Division } & Garden Designer & Public officer & Garden Show Judge & Professor & Other & Total \\
\hline Fixed place & $23(74.2)$ & $7(38.9)$ & - & $11(37.9)$ & $8(32)$ & $49(46.7)$ \\
Circulating place & $8(22.6)$ & $11(61.1)$ & $2(100.0)$ & $18(62.1)$ & $17(68)$ \\
\hdashline Total & $31(100.0)$ & $18(100.0)$ & $2(100.0)$ & $29(100.0)$ & $25(100.0)$ \\
$X^{2}(p)$ & & & $19.183 a\left(.038^{* *}\right)$ & & $105(100.0)$ \\
\hline
\end{tabular}

${ }^{*} p<0.10,{ }^{* *} p<0.05,{ }^{* * *} p<0.01$.

Table 8. Period of a garden show based on survey.

\begin{tabular}{|c|c|c|c|c|c|c|}
\hline Division & Garden Designer & Public officer & Garden Show Judge & Professor & Other & Total \\
\hline 1 weeks & $6(19.4)$ & $2(11.1)$ & $2(100.0)$ & $5(17.2)$ & $2(8.0)$ & $17(16.2)$ \\
\hline 2 weeks & $16(51.6)$ & $11(61.1)$ & - & $14(48.3)$ & $12(48.0)$ & $53(50.5)$ \\
\hline 1 month & $7(22.6)$ & $5(27.8)$ & - & $10(34.5)$ & $7(28.0)$ & $29(27.6)$ \\
\hline 3 month & $1(3.2)$ & - & - & - & $3(12.0)$ & $4(3.8)$ \\
\hline Other & $1(3.2)$ & - & - & - & $1(4.0)$ & $2(1.9)$ \\
\hline Total & $31(100.0)$ & $18(100.0)$ & $2(100.0)$ & $29(100.0)$ & $25(100.0)$ & $105(100.0)$ \\
\hline$X^{2}(p)$ & & & $46.790 \mathrm{a}(.001 *$ & & & \\
\hline
\end{tabular}


Table 9. Method for holding garden show based on survey.

\begin{tabular}{lcccccc}
\hline \multicolumn{1}{c}{ Division } & $\begin{array}{c}\text { Garden } \\
\text { Designer }\end{array}$ & $\begin{array}{l}\text { Public } \\
\text { officer }\end{array}$ & $\begin{array}{c}\text { Garden } \\
\text { Show Judge }\end{array}$ & Professor & Other & Total \\
\hline Inviting foreign Garden designer & $5(16.1)$ & $3(16.7)$ & $1(50.0)$ & $2(6.9)$ & $5(20.0)$ & $16(15.2)$ \\
Inviting domestic Garden designer & $25(80.6)$ & $2(11.1)$ & - & $1(3.4)$ & - & $28(26.7)$ \\
Discover a garden designer & $1(3.2)$ & $2(11.1)$ & $1(50.0)$ & $6(20.7)$ & $7(28.0)$ & $17(16.2)$ \\
Contest exhibit & - & $9(50.0)$ & - & $20(69.0)$ & $13(52.0)$ & $42(40.0)$ \\
Other & - & $2(11.1)$ & - & - & $2(1.9)$ \\
Total & $31(100.0)$ & $18(100.0)$ & $2(100.0)$ & $29(100.0)$ & $25(100.0)$ \\
$\mathrm{X}^{2}(p)$ & & & & $91.961 \mathrm{a}\left(.000^{* * *}\right)$ & $105(100.0)$ \\
\hline$* p<0.10, * * p<0.05, * * * p<0.01$. & & & &
\end{tabular}

Table 10. Scope of a garden show based on survey.

\begin{tabular}{lcccccc}
\hline \multicolumn{1}{c}{ Division } & $\begin{array}{c}\text { Garden } \\
\text { Designer }\end{array}$ & $\begin{array}{l}\text { Public } \\
\text { officer }\end{array}$ & $\begin{array}{c}\text { Garden } \\
\text { Show Judge }\end{array}$ & Professor & Other & Total \\
\hline Garden show & $2(6.5)$ & $1(5.6)$ & - & $2(6.9)$ & $1(4.0)$ & $7(5.7)$ \\
$\begin{array}{l}\text { Garden Show/ Goods public } \\
\text { relations and sales }\end{array}$ & $9(29.0)$ & $2(11.1)$ & - & $3(10.3)$ & $21(20.0)$ \\
$\begin{array}{l}\text { Garden Show/ Goods public } \\
\text { relations and sales/ Event }\end{array}$ & $20(64.5)$ & $14(77.8)$ & $2(100.0)$ & $24(82.8)$ & $17(68.0)$ & $77(73.3)$ \\
$\begin{array}{ll}\text { Other } \\
\text { Total }\end{array}$ & - & $1(5.6)$ & - & - & - & $1(1.0)$ \\
\hline
\end{tabular}

\section{6) Scope of garden shows}

According to the survey on the scope of garden shows, $73.3 \%$ of all respondents thought that it is necessary to include complex functions such as garden show, public relations and sales of goods and materials, and cultural events (Table 10). $5.7 \%$ of the respondents saw only the 'garden show' as part of the garden show, and $20 \%$ of them said the scope included garden show and publicity and sales of goods, generally showing low rates. By occupation, garden designers accounted for $64.5 \%$, public officers $77.8 \%$, and professors $82.8 \%$, all suggesting that the garden show performs complex functions. This implies that they perceive the garden show as a cultural venue that encompasses not only garden formation but also the garden industry and culture. Garden festivals are to develop programs that convey the regional culture and actively produce creative cultural activities in the region based on voluntary participation of local residents (Park, 2013). Garden shows are to show the fragments of culture that reflect the phases of the times and interesting diversity of enjoyment through garden designs beyond just being an exposition (Kwon, 2009). The
LAGA in Germany develops cultural programs associated with the cultural, social and historical attributes of the hosting city (Park, 2013). Garden shows are not only exhibitions for the eyes and experiences for the body, but also an opportunity to obtain new information (Jeong and Oh, 2016). Moreover, $79.2 \%$ of respondents showed great interest in plants, saying that they have experience visiting not only a garden show but a festival in Korea dealing with plants (Choi at al., 2016). As such, garden shows cover diverse fields.

Currently the Korea Garden Show is merely displaying gardens that provide ideas for garden designs. It is necessary to expand the scope of programs such as introducing the trend of garden culture and new plants.

\section{Direction for garden show management}

Based on the results above, this study sets the direction for garden shows in Korea as follows.

First, if associated with the city's facility planning or purpose of urban regeneration, it is necessary to hold the garden show by going around the relevant regions. Bundesgartenschau and 
Internationale Gartenschau in Germany are managing garden shows for permanent preservation with the purpose of urban regeneration. Park (2013) stated that the State Garden Show in Germany performs a key role in spreading the mood of garden culture to surrounding regions and transforming the entire city into a cultural place by holding the show in underdeveloped areas. There is no case in Korea in which garden shows were held for this purpose, but the venue can be changed depending on the purpose.

Second, for garden shows at the national level, it is necessary to seek plans for long-term planning and maintenance, provide budget support, and develop new state-led garden shows for national branding, and also to establish the venue to provide the latest trends and information about gardens to enhance the competencies of garden designers. Many garden designers from all over the world are visiting the Chelsea Flower Show in England and Le Festival International des de Chaumont-surLoire in France to obtain garden-related trends and information. Le Festival International des de Chaumont-sur-Loire also manages cafes and snack bars where the show gardens are built, while also managing stores that sell garden-related souvenirs, materials, and plants, enabling visitors to easily purchase related goods in addition to watching the show in convenience (You and Yang, 2013). Since garden shows are held sporadically in Korea and thus information is not concentrated, state-led garden shows must perform that role.

Third, it is important to make efforts to promote national awareness about garden culture by constantly publicizing and holding exhibitions, which must develop into a national marketing strategy for global publicity with a harmony of nature, history and culture in Korea. Le Festival International des de Chaumont-sur-Loire in France invites participation of garden designers in various nationalities, and is thus used as a useful means of publicity to expand the scope of the event (You and Yang, 2013). Garden shows must serve as a platform for garden-related cultural events (link to Open Garden) and information sharing (book publications, online data disclosure).

Fourth, there is a need for collaboration and division of work in terms of roles and functions in multiple backgrounds in order to settle the garden culture.

\section{Conclusion}

This study conducted a survey on garden-related experts from various backgrounds to set the direction and improve the management of the Korea Garden Show. The results showed that many of them considered spreading the garden culture as the purpose and function of garden shows, and they thought it is necessary to provide a theme or topic for the show. They preferred April-May to hold the show, while there was a similar number of respondents saying that the event must take place in a fixed place or must be on a provincial tour. Many of them also responded that the show must last for 2 weeks. As for the scope of the garden shows, they responded that it is necessary to include multiple functions in addition to the garden show itself, such as public relations and sales of goods as well as cultural events.

Based on the results above, this study suggests the following direction for the management of the Korea Garden Show.

First, participants may come up with ideas through diversity within limitations by providing certain themes and topics like the current management plan in garden shows. They can also broaden the scope of application and develop various exhibition techniques by using plant materials diversely to express the theme.

Second, April and May are most suitable to hold the show considering the diversity of plant materials and the flowering season, and 2 weeks of the show seems adequate considering the operation and management issues of the show gardens and the needs of experts.

Third, it is necessary to first increase sustainability of the garden show and promote public awareness by holding the show at a fixed place, after which it should be on a tour of different cities and provinces to expand the base of gardens and develop into a garden show that conveys various distinctive features of the regions. Furthermore, it is necessary to ponder over the public functions and social contribution with regard to whether the garden show is a temporary show or must be maintained for urban regeneration.

Fourth, the Korea Garden Show merely provides garden design ideas with show gardens. However, there is a high demand for expanding the scope of the garden show. Thus, it is necessary to internally stabilize the contents associated with 
the industry in forming the garden show (selling and publicizing garden materials, etc.), and introduce garden design techniques as well as various garden industry materials such as state-ofthe-art materials or unknown wildflowers or new varieties.

This must be concentrated in a state-led garden show so that citizens can obtain necessary information. Moreover, it is also necessary to reinforce its role as a platform to settle the garden culture by holding symposiums that provide the latest gardenrelated trends and information.

Managing the Korea Garden Show based on these implications will have a greater influence on spreading the garden culture, which can be applied to other garden shows held in provincial regions. Furthermore, there must be constant research and efforts for specific and diverse programs within the garden show for sustainable management.

\section{References}

Choi, W.K., H.Y. Jin, and J.H. Song. 2016. Analysis of Users Recognition on Wildflowers as Gardening Plants. J. People Plants Environ. 20(1):81-93.

Chung, J.H., J.M. Ahn, and M.R. Kang. 2015. Development of SFC and propose of application measures on garden design-focusing on gyeonggi garden cultural Fair and Seoul Garden Expo-. J. Korean Inst. Gard. Des. 1(1):48-56.

Geddes-Brown and Lelie 2005. Chelsea: The greatest flower show on earth. Dorling Kindersley.

Kwon, J.W. 2009. A look at visual design interpretation of garden space through Garden Festival Chaumont. J. Environ. Stud. 48: 69-80.

Jeong, B.B. 2015. A Study on the tendency of herbaceous planting of designer's garden in Suncheon bay garden expo site. MS thesis, Suncheon Univ., Suncheon, Korea.

Jeong, J.M. and J.H. Oh. 2016. A study on the motivation of garden expo visitors -focusing on the Gyeonggi garden culture expo-. J. Korean Soc. People Plants Environ. 19(5):533-538

Lee, J.R. 2014. Determinants and processes of regional policy on the international garden exposition Suncheon Bay Korea 2013. J. Korean Geogr. Soc. 49(6):849-864.

Lee, J.R., K.B. Nam, S.H. Chi, and J.H. Ahn. 2015. The impacts on the change of urban image of the international garden exposition Suncheon Bay Korea 2013. J. Korean Assoc. Reg. Geogr. 21(2): 273-285.

Park, E.Y. and Y.R. Park. 2011. Texture characteristics of herbaceous plants used in the relaxation gardens at the Chelsea flower show 2010. J. Korean Soc. People Plants Environ. 14(1):51-57.

Park, E.Y. and H.S. Lee. 2014. Analysis of preferences and a sense of healing among the healing gardens at the 2014 Korean garden show. J. Korean Soc. People Plants Environ. 17(5):379-385.

Park, J.K. 2013. A Study on the urban characteristics of design for urban regeneration based on cultural strategy-focused on the case of ruhrgebiet, germany-. J. Korean Inst. Ecol. Archit. Environ. 13(4):75-86

Song, J.H., H.Y. Jin, H.J. Maeng, W.K. Choi, Y.J. Song, Y.C. Jeon, and C.H. Lee. 2016. Investigation for satisfaction of facilities and programs of 'garden playground' of korea national arboretum for spreading garden cultures. Environ. Educ. 29(3):321-335.

Yoon, S.J. 2009. Garden design trends on the chelsea flower show in england between 2001 and 2009. J. Environ. Stud. 48:99-117.

Yoon, S.J., J.W. Kwon, and K.P. Hong. 2014. A Historical study on the propagation and diffusion of the traditional japanese garden in foreign countries - focused on world's fairs between 1867 and 1939-. J. Kor. Institut. Trad. Landscape Architecture 32(2):167-179.

You, H.Y. and G.S. Yang. 2013. L'etude pour promouvoir une ville a travers le festival des jardins -le cas du festival international des jardins de chaumont-sur-loire- Assoc. Cultur. Franco-Coreene 27:213-243. 